*Proceedings*

\title{
Dual/Bi-Stage Curing of Nanocomposites from Renewable Resources upon Volumetric Expansion ${ }^{\dagger}$
}

\author{
Fabio Blaschke ${ }^{1,2}$, Philipp Marx ${ }^{1,3}$ and Frank Wiesbrock 1,* \\ 1 Polymer Competence Center Leoben GmbH, Roseggerstrasse 12, 8700 Leoben, Austria. \\ fabio.blaschke@pccl.at (F.B.); philipp.marx@pccl.at (P.M.) \\ 2 Institute for Chemistry and Technology of Materials, TU Graz, NAWI Graz, Stremayrgasse 9, 8010 Graz, \\ Austria \\ 3 Chair of Chemistry of Polymeric Materials, Montanuniversitaet Leoben, Otto-Gloeckel-Str. 2, 8700 Leoben, \\ Austria \\ * Correspondence:Correspondence: frank.wiesbrock@pccl.at; Tel.: +43-3842-42962-42 \\ + Presented at the First International Conference on “Green" Polymer Materials 2020, 5-25 November 2020; \\ Available online: https://cgpm2020.sciforum.net/.
}

Published: 3 November 2020

\begin{abstract}
Nowadays, a large part of polymers for technical application is still obtained from petrochemicals, despite the more critical review by society. In this work, novel nanodielectrics based on renewable resources were developed. For this purpose, poly(2-oxazoline)s (POx), which can be referred to as pseudo-polyamides, were synthesized from renewable resources and compared with commercially available Nylon 12, which is derived from petrochemicals. The monomers 2-nonyl-2oxazozoline and 2-dec-9'-enyl-2-oxazoline were synthesized from coconut oil and castor oil in solvent-free syntheses according to the Henkel Patent; the corresponding copoly(2-oxazoline)s were synthesized in energy-efficient fashion in microwave reactors under autoclave conditions. Both types of polyamides (2 variations: POx and Nylon 12) were filled with inorganic nanoparticles (4 variations: no filler, submicro-scaled $\mathrm{BN}$, nano- and micro-scaled $\mathrm{AlN}$ ) and/or expanding monomers, namely spiro-orthoesters ( 3 variations: 0,15 , and $30 \mathrm{wt.}$ - $\%$ ), yielding a $2 \times 4 \times 3=24-$ membered material library. All polymers were crosslinked according to a newly developed thermally-initiated dual/bi-stage curing system. Intense physico-chemical and dielectric characterization revealed that the relative volume expansion was in the range of 0.46 to 2.48 vol.- $\%$ for the Nylon 12 samples and in the range of 1.39 to 7.69 vol.- $\%$ for the POx samples. Hence, the formation micro-cracks or micro-voids during curing is significantly reduced. The dielectric measurements show competitive dielectric behaviour of the 'green' POx samples in comparison with the fossil-based Nylon 12 samples at a frequency of $40 \mathrm{~Hz}$.
\end{abstract}

Keywords: polymer from renewable resources; poly(2-oxazoline); pseudo-polyamide; nanodielectric; expanding monomer

\section{Introduction}

The future challenges for polymer-based dielectric materials will be manifold. An important driving-force for material development is the increasing heat development in electronic devices, originating from the increasing power density. Recently, ceramic fillers have been evaluated as additives to polymer-based dielectrics because of their intrinsic thermal conductivity, which is of 1 to 2 orders of magnitude higher than that of oxided-based fillers such as $\mathrm{Al}_{2} \mathrm{O}_{3}$ and silica $\mathrm{SiO}_{2}$ [1]. It was shown by transmission electron microscopy (TEM) that BN tends to agglomerate in a manifold of types of polymer matrices [2]. It was shown that the usage of hybrid-filler systems composed of $\mathrm{Al}_{2} \mathrm{O}_{3}$ and $\mathrm{AlN}$ with different particle sizes can overcome the problem of forming inflexible voids [3]. 
This study aimed at the development of novel polymer-based composites for future employment as dielectrics. Based on the state-of-the-art knowledge of inorganic fillers, micro-scaled hexagonal boron nitride hBN, nano- and micro-scaled aluminium nitride n-AlN and $\mu$-AlN particles, as well as mixtures of the types of particles were added to the polymer matrices to ensure a higher thermal conductivity.

An additional challenge is the volumetric shrinkage during crosslinking, which leads to the formation of micro-cracks, micro-voids and delamination, deteriorating the insulation properties [4]. Therefore, a spiroorthoester SOE was added in different contents to the base polymer material. The SOE exhibited an unsaturated $\mathrm{C}=\mathrm{C}$ bond that enabled its covalent attachment to the polymer matrices (see hereinafter). By employment of the $\mathrm{SOE}$, the volumetric shrinkage during the curing reaction should be minimized or in the best case completely counter-balanced, yielding networks that are volume-neutral during curing.

An additional important aspect for the design-of-experiments DoE/material choices originated from the fact that the vast majority of polymers used in microelectronics and high-voltage engineering are obtained from petrochemicals: In society, a more critical view has evolved considering aspects of sustainability and environmental challenges [5]. Therefore, it is highly recommendable to replace the organic part of composites with polymers made from renewable resources in order to contribute to environmental protection and lay the foundation for future generations of non-fossil-based materials. A promising alternative to fossil-based polyamides is offered by poly(2-oxazolines), which can be regarded as 'pseudo'-polyamides. Like polyamides, (co)poly(2-oxazoline)s are known for their high temperature stability [6]. 2-Oxazoline monomers with long aliphatic chains can be derived from fatty acids (Figure 1). Precedent studies have already shown that the values of permittivity, loss factor and conductivity of this class of material are in the same range as for polyamides, classifying these materials as medium insulators [7].

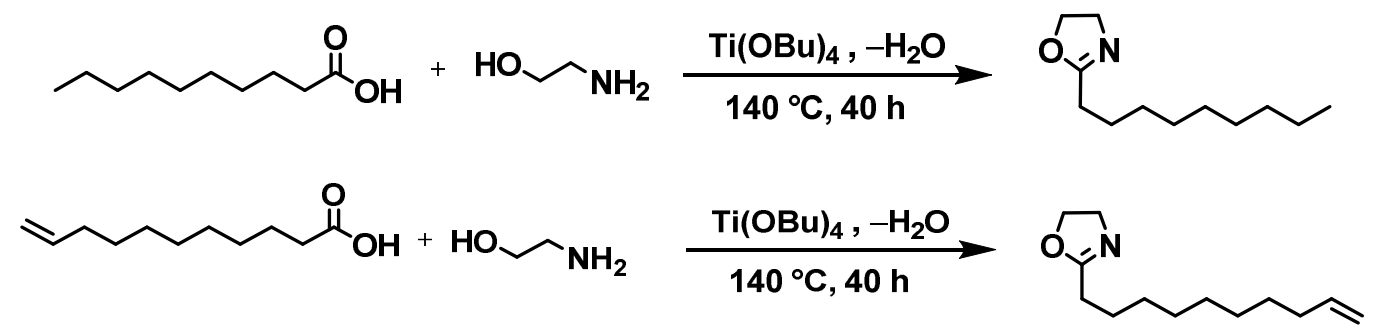

Figure 1. Reaction scheme of the synthesis of 2-oxazoline monomers from fatty acids (of renewable resources).

In summary, in this study, different samples of polymer blends and composites from renewable polymers and fossil-based polymers were prepared. Two 12-membered material libraries (one for the Nylon 12- and one for the copoly(2-oxazoline)-based matrices) were fundamentally characterized by physico-chemical and dielectric properties in order to establish the correlations between the structure and the resulting properties.

\section{Experiments}

\subsection{Materials and Methods}

Allyl glycidyl ether, boron trifluoride diethyl etherate, $\gamma$-butyrolactone, dicumyl peroxide, ethanolamine, methyl tosylate, titanium(IV) butoxide, trimethylamine, decanoic acid, and undec-10enoic acid were purchased from Sigma Aldrich (Vienna, Austria). Aluminum(III)nitride (particle size 1.0-15.0 $\mu \mathrm{m}$ ), 1-Butylpyridin-1-ium hexafluorophosphate(V) were received from ABCR (Karlsruhe, Germany). Aluminium(III)nitride (particle size $50 \mathrm{~nm}$ ) was purchased from loLiTec (Heilbronn, Germany). Boron nitride (particle size $70 \mathrm{~nm}$ ) was purchased from MKNano (Missiauga, Canada). Nylon 12 (particle size 25-30 $\mu \mathrm{m}$ ) was purchased from Goodfellow Limited (Hamburg, Germany). All chemicals were used as received, except for methyl tosylate that was distilled prior to use. 
The microwave-assisted polymerization was performed with the Synthos 3000 Microwave Synthesis Platform from Anton Paar GmbH in screwable Wheaton ${ }^{\circledR}$ glass vials $(15 \times 46 \mathrm{~mm})$ with a Rotor 64. All NMR measurements were performed with a Bruker Advance III $300 \mathrm{MHz}$ spectrometer. As solvent, $\mathrm{CDCl}_{3}$ with an internal standard of $0.03 \%$ TMS were used. Infrared spectroscopy was performed with an Alpha Fourier-Transform Infrared Spectrometer with ATR support. The scan area was from 400 to $4000 \mathrm{~cm}^{-1}$, and 48 scans were performed for each measurement. For the determination of the average molar mass of the polymers, GPC analyses were performed with a Merck Hitachi L6000A pump, a column from Polymer Standards Service column $(8 \backslash 300 \mathrm{~mm}$ STV linear XL $5 \mu \mathrm{m}$ grade size), and a differential refractometer Waters 410 detector. As solvent, THF was used. For the preparation of the PA and POx test specimens, a Collin P 200 Laboratory Platen Press was used. The thermogravimetry and DSC measurements were performed with the Netzsch STA 449C Jupiter device coupled with quadrupole mass spectrometry. The temperature range was from 20 to $550{ }^{\circ} \mathrm{C}$ with a heating rate of $10 \mathrm{~K} \mathrm{~min}^{-1}$. The measurement was performed under helium atmosphere. Dielectric characterization was performed with a SPECTANO 100 from OMICRON Lab. All samples were characterized in a frequency range of $0.1 \mathrm{~Hz}$ to $5 \mathrm{kHz}$.

\subsection{Synthesis of the Monomers $\mathrm{Dec}^{=} \mathrm{Ox}$, NonOx, and the $S O E$}

NonOx: NonOx was synthesized according a Henkel Patent [8]. In a $500 \mathrm{~mL}$ three-neck roundbottom flask equipped with a magnetic stirring bar and a reflux condenser, $135 \mathrm{~g}$ of decanoic acid ( $0.78 \mathrm{~mol}, 1$ equivalent), $71 \mathrm{~mL}$ of ethanol-2-amine (1.18 mol, 1.5 equivalents) and as well $1.4 \mathrm{~mL}$ of the catalyst titanium(IV) $n$-butoxide ( $3.92 \mathrm{mmol}, 0.005$ equivalent) were stirred under reflux at $160^{\circ} \mathrm{C}$ for $24 \mathrm{~h}$. Further amounts of $1.4 \mathrm{~mL}$ of the catalyst titanium(IV) $n$-butoxide (3.92 mmol, 0.005 equivalent) were added after 20 and $24 \mathrm{~h}$. After that, the reflux condenser was removed, and the mixture was stirred for additional $12 \mathrm{~h}$ to remove the reaction water. The crude NonOx product was obtained via fractional distillation under vacuum $\left(125{ }^{\circ} \mathrm{C}, 6 \mathrm{mbar}\right)$, yielding a yellow liquid. Purification by column chromatography with chloroform yielded a colourless viscous liquid of pure NonOx. The yield was $53.3 \%$ (82.36 g).

${ }^{1} \mathrm{H}-\mathrm{NMR}\left(300 \mathrm{MHz}, 298 \mathrm{~K}, \mathrm{CDCl}_{3}\right): \delta(\mathrm{ppm})=0.88(3 \mathrm{H}, \mathrm{t}), 1.27(12 \mathrm{H}, \mathrm{s}), 1.63(2 \mathrm{H}, \mathrm{t}), 2.26(2 \mathrm{H}, \mathrm{t})$, $3.82(2, \mathrm{t}), 4.21(2 \mathrm{H}, \mathrm{t}) .{ }^{13} \mathrm{C}-\mathrm{NMR}\left(75 \mathrm{MHz}, 298 \mathrm{~K}, \mathrm{CDCl}_{3}\right): \delta(\mathrm{ppm})=14.1,22.6,25.9,28.0,29.2,29.4$, 31.8, 54.3, 67.1, 168.7. IR (ATR): $v\left(\mathrm{~cm}^{-1}\right)=2923,2854,1688,1464,1362,1231,1165,986,950,908,754$, 722.

Dec=Ox: Dec=Ox was synthesized according a Henkel Patent [8]. In a $500 \mathrm{~mL}$ three-neck roundbottom flask equipped with a magnetic stirring bar and a reflux condenser, $135 \mathrm{~g}$ of undec-10-enoic acid ( $0.73 \mathrm{~mol}, 1$ equivalent), $70 \mathrm{~mL}$ of ethanol-2-amine (1.17 mol, 1.6 equivalents) and as well $1.3 \mathrm{~mL}$ of the catalyst titanium(IV) $n$-butoxide ( $3.66 \mathrm{mmol}, 0.005$ equivalent) were stirred under reflux at 140 ${ }^{\circ} \mathrm{C}$ for $24 \mathrm{~h}$. Further amounts of $1.3 \mathrm{~mL}$ of the catalyst titanium(IV) $n$-butoxide ( $3.66 \mathrm{mmol}, 0.005$ equivalent) were added after 20 and $24 \mathrm{~h}$. After that, the reflux condenser was removed, and the mixture was stirred for additional $12 \mathrm{~h}$ to remove the reaction water. The crude Dec=Ox product was obtained via fractional distillation under vacuum $\left(116{ }^{\circ} \mathrm{C}, 6 \mathrm{mbar}\right)$, yielding a yellow liquid. Purification by column chromatography with chloroform yielded a colourless viscous liquid of pure Dec $=$ Ox. The yield was $68.4 \%$ (104.9 g).

${ }^{1} \mathrm{H}-\mathrm{NMR}\left(300 \mathrm{MHz}, 298 \mathrm{~K}, \mathrm{CDCl}_{3}\right): \delta(\mathrm{ppm})=1.23(10, \mathrm{~s}), 1.55(2, \mathrm{t}), 1,95(2 \mathrm{H}, \mathrm{d}), 2.19(3 \mathrm{H}, \mathrm{t}), 3,74$ $(2, \mathrm{t}), 4,14(2 \mathrm{H}, \mathrm{t}), 4,88(2 \mathrm{H}, \mathrm{m}), 5,72(1 \mathrm{H}, \mathrm{m}) .{ }^{13} \mathrm{C}-\mathrm{NMR}\left(75 \mathrm{MHz}, 298 \mathrm{~K}, \mathrm{CDCl}_{3}\right): \delta(\mathrm{ppm})=25.9,27.9$, $28.9,29.0,29.2,29.3,31.8,54.3,67.1,114.1,139.1,168.6$. IR (ATR): $v\left(\mathrm{~cm}^{-1}\right)=2924,2853,1668,1640$, $1461,1432,1385,1361,1227,1167,987,952,907,723$.

SOE: The spiro-orthoester was synthesized according to the method described by Marx et al.[9]. $11.41 \mathrm{~g}$ ( $0.1 \mathrm{mmol}, 1.0$ eq.) of allyl glycidyl ether were added with a dropping funnel over a period of $40 \mathrm{~min}$ to a mixture of $0.46 \mathrm{~g}$ ( $3.24 \mathrm{mmol})$ of $\mathrm{BF}_{3}$-OEt2 and $52 \mathrm{~g}$ ( $0.6 \mathrm{~mol}, 6.0 \mathrm{eq}$.) of $\gamma$-butyrolactone under a nitrogen atmosphere and cooling with a water bath. After stirring at room temperature for 1 $\mathrm{h}$, the reaction was quenched by the addition of $0.36 \mathrm{~g}(3.56 \mathrm{mmol})$ of NEt3. The mixture was extracted with $\mathrm{CH}_{2} \mathrm{Cl}_{2}(40 \mathrm{~mL})$ and $\mathrm{H}_{2} \mathrm{O}(20 \mathrm{~mL})$. The organic layer was dried over $\mathrm{Na}_{2} \mathrm{SO}_{4}$, and the solvent was 
evaporated under reduced pressure. For purification, the crude product was distilled under reduced pressure yielding $19.2 \mathrm{~g}(48 \mathrm{mmol}, 48 \%)$ of a colourless liquid (boiling point $115^{\circ} \mathrm{C} / 0.1 \mathrm{mbar}$ ).

${ }^{1} \mathrm{H}-\mathrm{NMR}\left(300 \mathrm{MHz}, 298 \mathrm{~K}, \mathrm{CDCl}_{3}\right) \delta(\mathrm{ppm})=1.90-2.06(\mathrm{~m}, 2 \mathrm{H}), 2.11-2.20(\mathrm{~m}, 2 \mathrm{H}), 3.42-3.43(\mathrm{~m}$, $0.5 \mathrm{H}), 3.44-3.50(\mathrm{~m}, 1 \mathrm{H}), 3.52-3.64(\mathrm{~m}, 0.5 \mathrm{H}), 3.67-3.75(\mathrm{~m}, 1 \mathrm{H}), 3.85-4.09(\mathrm{~m}, 4 \mathrm{H}), 4.11-4.30(\mathrm{~m}, 1 \mathrm{H})$, 4.32-4.43 (m, 0.5 H), 4.43-4.48 (m, 0.5H), 5.17-5.30 (m, $2 \mathrm{H}), 5.85-5.91(\mathrm{~m}, 1 \mathrm{H}) .{ }^{13 \mathrm{C}-\mathrm{NMR}}(300 \mathrm{MHz}$, $\left.298 \mathrm{~K}, \mathrm{CDCl}_{3}\right) \delta(\mathrm{ppm})=24.1,24.2,32.7,32.9,66.5,66.9,67.2,70.3,71.5,72.4,72.5,74.3,75.3,117.3$, 117.4, 129.5, 129.7, 134.4. IR (ATR) $v\left(\mathrm{~cm}^{-1}\right)=3081,2955,2879,1776,1737,1647,1458,1332,1244,1195$, 1130, 84 1040, 954, 922, 867, 807, 736.

\subsection{Synthesis of the Copolymer Poly(2-Nonyl-2-Oxazoline)-Stat-Poly(2-dec-9'-enyl-2 oxazoline)}

The copolymerization of $\mathrm{Dec}=\mathrm{Ox}$ and NonOx was performed via microwave-assisted polymerization in a scale of 25 g. 20 equiv. of $\mathrm{Dec}^{=} \mathrm{Ox}$ and 80 equiv. of NonOx were mixed. As initiator, methyl tosylate MeOTs (1 equiv.) was added; as solvent, acetonitrile ACN was used. Under autoclave condition at $140{ }^{\circ} \mathrm{C}$ and stirring for $2 \mathrm{~h}$ in sealed reaction vials, the copolymer pNonOx80stat-pDec=Ox $x_{20}$ was obtained via a cationic ring-opening (co-)polymerization CROP. A white powder was obtained after rotary evaporation of the solvent, grinding in the mortar and further drying.

${ }^{1} \mathrm{H}-\mathrm{NMR}\left(300 \mathrm{MHz}, 298 \mathrm{~K}, \mathrm{CDCl}_{3}\right): \delta(\mathrm{ppm})=0.81(274 \mathrm{H}), 1.19(1275 \mathrm{H}), 1.51(211 \mathrm{H}), 1.97(45$ $\mathrm{H}), 2.17(208 \mathrm{H}), 3.37(400 \mathrm{H}), 4.88(40 \mathrm{H}), 5.74(20 \mathrm{H}) .{ }^{13} \mathrm{C} \mathrm{NMR}\left(75 \mathrm{MHz}, 298 \mathrm{~K}, \mathrm{CDCl}_{3}\right): \delta(\mathrm{ppm})=$ 14.1, 22.7, 25.2, 25.4, 29.0, 29.2, 29.4, 29.6, 32.0, 33.0, 33.8, 43.3, 45.3, 114.2, 139.1, 173.2, 173.7. IR (ATR): $v\left(\mathrm{~cm}^{-1}\right)=2921,2852,1640,1462,1430,1183,1177,907,773,722 . \mathrm{GPC}: \mathrm{M}_{\mathrm{w}}=17.6 \mathrm{kDa} ; \mathrm{M}_{\mathrm{n}}=8.87 \mathrm{kDa}$; $\mathrm{Đ}=1.81$.

\subsection{Preparation of the Test Specimens}

For the Pox system, poly(2-nonyl-2-oxazoline)-stat-poly(2-dec-9'-enyl-2-oxazoline), and for the PA-system, Nylon 12 was used. For the crosslinkling of the POx sample, $5 \mathrm{~mol}-\%$ of dicumyl peroxide (referred to the double bonds of the copolymer) were added. For the crosslinking of the PA samples, 2 wt.- $\%$ of dicumyl peroxide (referred to the total amount of Nylon 12) were added. For the preparation of the POx/PA samples with SOE (15 or $30 \mathrm{wt} .-\%$ referred to the total amount of POx/PA) were added. The amount of the additional initiator 1-butylpyridin-1-ium hexafluoro phosphate $(\mathrm{V})$ was 5 wt.- $\%$ (referred to the amount of SOE). All mixtures were homogenized by grinding.

Test specimen of the PA and POx were prepared in a Platen Press. A temperature of $180^{\circ} \mathrm{C}$ and a pressure of $40 \mathrm{bar}$ were applied for $20 \mathrm{~min}$. A steel plate was covered with a $0.2 \mathrm{~mm}$ thick PTFE-foil from Haberkorn and a stainless-steel form was placed on it. The respective amount of the powder mixture was added in the stainless-steel form (squared, circled or rectangular shape). The top was again covered with a PTFE-foil and a steel plate. The composite samples were dried in a vacuum oven at $60^{\circ} \mathrm{C}$ and $1 \mathrm{mbar}$ for $72 \mathrm{~h}$.

\section{Results and Discussion}

\subsection{Copolymer Synthesis}

For the synthesis of polymers from renewable resources, the Henkel patent was chosen to obtain the two monomers NonOx and $\mathrm{Dec}=\mathrm{Ox}$ from fatty acids. Via a microwave-assisted copolymerization, colorless poly(2-nonyl-2-oxazoline)-stat-poly(2-dec-9'-enyl-2-oxazoline) was obtained (Figure 2). The polymer was characterized with ${ }^{1} \mathrm{H}-\mathrm{NMR},{ }^{13} \mathrm{C}-\mathrm{NMR}$, FT-IR, GPC, TGA and DSC measurements. The NMR reveals high product purity and confirms the targeted stoichiometric amounts of the repetition units of NonOx and Dec=Ox. The TGA shows that the copoly(2-oxazoline) exhibits a high thermal stability; by DSC measurements, the glass-transition temperature $\mathrm{T}_{\mathrm{g}}=40.5^{\circ} \mathrm{C}$ and the melting point $\mathrm{T}_{\mathrm{m}}=138.0^{\circ} \mathrm{C}$ were determined. 


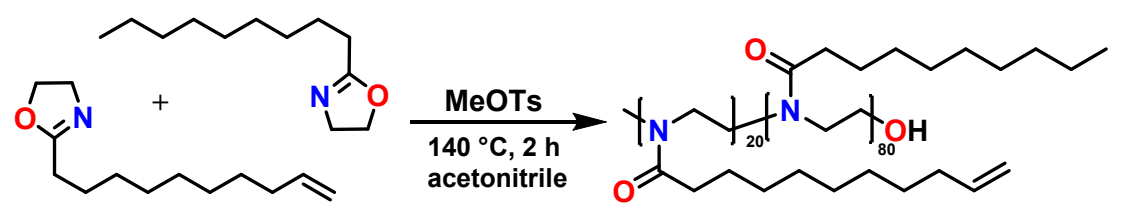

Figure 2. Schematic representation of the copolymerization of $\mathrm{NonOx}$ and $\mathrm{Dec}^{=} \mathrm{Ox}$.

Curing of the polymer matrices. For the (combined) radical-induced crosslinking of POx/PA, respectively, and the radical-induced covalent attachment of the SOE to the polymer matrix with simultaneous cationic ring-opening (and expansion) of the SOE, a thermally-triggered dual/bi-stage curing system needed to be developed. In addition to the radical initiator dicumyl peroxide, the cationic initiator 1-butylpyridin-1-ium hexafluorophosphate(V) to was used. As SOE with pendant $\mathrm{C}=\mathrm{C}$ double bond, 2-((allyloxy)methyl)-1,4,6-trioxaspiro[4.4] nonane was added to the polymer matrix.

\subsection{Library Design}

Composite test specimens of Nylon 12 and POx were successfully produced (2 variations), with no SOE or SOE in contents of 15 or $30 \mathrm{wt.}$ - $\%$ (3 variations), and containing no fillers or inorganic fillers in a content of 40 wt.- $\%$ hBN, $20 / 20$ wt.- $\%$ of n-AlN/ $\mu$-AlN , and 20/10/10 wt.- $\%$ of hBN/n-AlN/ $\mu$-AlN (4 variations). This DoE yielded two $3 \times 4=12$-membered matrix libraries (Figure 3). Test specimens were produced in squared shape with an area of $8 \times 8 \mathrm{~cm}$ and a height of $300 \mu \mathrm{m}$ and circular shape with diameters of $4 \mathrm{~cm}$ and a height of $300 \mu \mathrm{m}$.
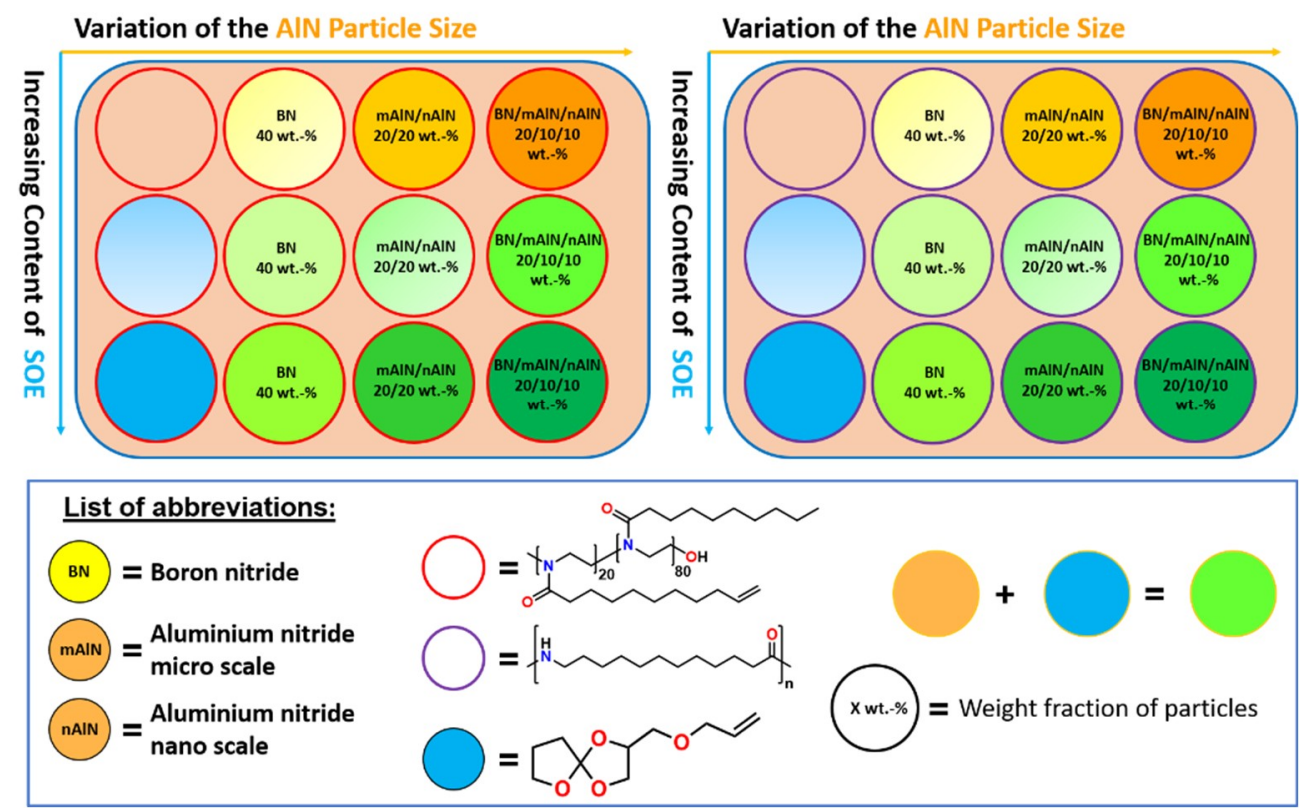

Figure 3. Schematic representation of the material libraries of the composite materials.

\subsection{Determination of the Volumetric Expansion}

In order to determine the influence of the SOE on the volumetric change during the crosslinking of the polymer, the mass $(\mathrm{m})$ and the dimensions of each sample were measured. The thickness and length of the test specimens were determined with a caliper at 8 different measuring points. The volume $(\mathrm{V})$ of the test specimens was calculated from the mean values of the thickness and the length. The density $(\rho)$ was calculated by the following formula (Equation (1); Tables 1 and 3):

$$
\rho=\frac{m}{V}
$$


The volumetric expansions were calculated relative to the density of the specimen without SOE (Tables 2 and 4). The addition of SOE induces a volume expansion compared to the sample without the SOE. The relative volumetric expansion of the POx samples due to the addition of SOE in a content of 15 (30) wt.- $\%$ is in the range of $1.23-1.54 \%$ (4.29-7.69\%). The relative volume expansion of the Nylon 12 samples due to the addition of SOE in a content of 15 (30) wt.- $\%$ is smaller than $1 \%$ (in the range of $1.41-2.48 \%$ ).

Hence, the POx samples show higher volumetric expansion than the Nylon 12 samples. A possible explanation can be the steric hindrance in the condensed phase due to the hydrophobic (nonyl and decenyl) side-chains in the POx system, which, in final consequence, induces different separation among the polyamide and polyester/polyether phases than in the Nylon 12. This phenomenon needs to be subjected to further investigation. Nevertheless, volume shrinkage could be reduced in both polymer systems.

Table 1. Density in $\mathrm{g} \cdot \mathrm{cm}^{-3}$ of the the POx samples.

\begin{tabular}{|c|c|c|c|c|}
\hline $\begin{array}{c}\text { SOE } \\
\text { wt.-\% }\end{array}$ & $\begin{array}{c}\text { No Particles: } \\
{\left[\mathrm{g} \cdot \mathrm{cm}^{-3}\right]}\end{array}$ & $\begin{array}{c}\text { hBN, } \\
40 \mathrm{wt.} \% \%: \\
{\left[\mathrm{g} \cdot \mathrm{cm}^{-3}\right]}\end{array}$ & $\begin{array}{c}\text { n-AIN/ } \mu-A I N, \\
20 / 20 \text { wt.- } \%: \\
{\left[\mathrm{g} \cdot \mathrm{cm}^{-3}\right]}\end{array}$ & 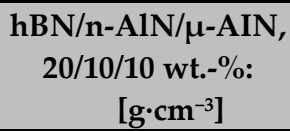 \\
\hline 0 & 1.05 & 1.23 & 1.29 & 1.29 \\
\hline 15 & 1.04 & 1.21 & 1.24 & 1.23 \\
\hline 30 & 1.01 & 1.17 & 1.19 & 1.19 \\
\hline
\end{tabular}

Table 2. Relative volumetric expansion of the POx samples.

\begin{tabular}{|c|c|c|c|c|}
\hline $\begin{array}{c}\text { SOE } \\
\text { wt.- } \%\end{array}$ & $\begin{array}{c}\text { No Particles: } \\
\text { V }_{\text {rel }}[\%]\end{array}$ & $\begin{array}{r}\text { hBN, } \\
40 \text { wt.-\%: } \\
\mathrm{V}_{\text {rel }}[\%]\end{array}$ & $\begin{array}{c}\text { n-AlN } / \mu-A 1 N, \\
20 / 20 \text { wt.- } \% \\
V_{\text {rel }}[\%]\end{array}$ & 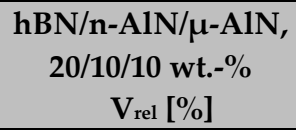 \\
\hline 0 & - & - & - & - \\
\hline 15 & 1.54 & 1.39 & 3.70 & 4.97 \\
\hline 30 & 4.39 & 4.84 & 7.69 & 7.50 \\
\hline
\end{tabular}

Table 3. Density in $\mathrm{g} \cdot \mathrm{cm}^{-3}$ of the the Nylon 12 samples.

\begin{tabular}{|c|c|c|c|c|}
\hline $\begin{array}{c}\text { SOE } \\
\text { wt.- } \%\end{array}$ & $\begin{array}{c}\text { No Particles: } \\
{\left[\mathrm{g} \cdot \mathrm{cm}^{-3}\right]}\end{array}$ & $\begin{array}{c}\mathrm{hBN}, \\
40 \mathrm{wt.} \% \% \\
{\left[\mathrm{~g} \cdot \mathrm{cm}^{-3}\right]}\end{array}$ & $\begin{array}{c}\text { n-AIN/ } \mu-A I N, \\
\text { 20/20 wt.-\%: } \\
{\left[\mathrm{g} \cdot \mathrm{cm}^{-3}\right]}\end{array}$ & $\begin{array}{c}\mathrm{hBN} / \mathrm{n}-\mathrm{AlN} / \mu-\mathrm{AIN} \\
\text { 20/10/10 wt.-\%: } \\
{\left[\mathrm{g} \cdot \mathrm{cm}^{-3}\right]}\end{array}$ \\
\hline 0 & 1.02 & 1.21 & 1.26 & 1.28 \\
\hline 15 & 1.01 & 1.20 & 1.25 & 1.27 \\
\hline 30 & 0.99 & 1.19 & 1.24 & 1.26 \\
\hline
\end{tabular}

Table 4. Relative volumetric expansion of the Nylon 12 samples.

\begin{tabular}{|c|c|c|c|c|}
\hline $\begin{array}{c}\text { SOE } \\
\text { wt.-\% }\end{array}$ & $\begin{array}{c}\text { No Particles: } \\
\text { V rel }[\%]\end{array}$ & $\begin{array}{c}\text { hBN, } \\
40 \text { wt.-\%: } \\
\text { V rel [\%] } \\
\end{array}$ & 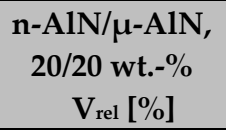 & $\begin{array}{c}\text { hBN/n-AlN/ } \mu-A l N \\
\text { 20/10/10 wt.-\% } \\
V_{\text {rel }}[\%]\end{array}$ \\
\hline 0 & - & - & - & - \\
\hline 15 & 0.98 & 0.84 & 0.46 & 0.84 \\
\hline 30 & 2.48 & 1.41 & 1.92 & 1.60 \\
\hline
\end{tabular}

\subsection{Dielectric Properties of the Polymer Networks and the Corresponding Composites}

By dielectric spectroscopy with a SPECTANO 100 from OMICRON Lab, all specimens were characterized in a frequency range of $0.1 \mathrm{~Hz}$ to $5 \mathrm{kHz}$. The permittivity (real part, as well as the imaginary part) increases with decreasing frequencies for all samples. In general, the permittivity increases in samples that contain SOE, which has been referred to the increasing free volume due to the volumetric expansion. The dielectric properties of the Nylon 12 and the POx samples were compared at a low frequency of $40 \mathrm{~Hz}$ on the example of the loss factor tand (Tables 5 and 6). The 
unfilled POx sample show nearly the same loss factors as the Nylon 12 samples. Additionally, the copoly(2-oxazoline)s filled with $\mathrm{hBN}$ and $\mathrm{n}$-AlN/ $\mu$-AlN are competitive with the PA samples as well. However, the Nylon 12 samples with the $\mathrm{hBN} / \mathrm{n}-\mathrm{AlN} / \mu$-AlN filler combination show the lowest loss factors. All specimens exhibit loss factors tan $\delta<1$ and can be considered as good dielectrics [7].

Table 5. Dielectric loss tan of the POx samples at frequency of $40 \mathrm{~Hz}$.

\begin{tabular}{|c|c|c|c|c|}
\hline SOE wt.-\% & $\begin{array}{c}\text { No Particles: } \\
\tan \delta\end{array}$ & $\begin{array}{c}\text { hBN, } \\
40 \text { wt.- } \%: \\
\tan \delta \\
\end{array}$ & $\begin{array}{c}\text { n-AlN } / \mu-\mathrm{AlN}, \\
\text { 20/20 wt.- } \%: \\
\tan \delta\end{array}$ & 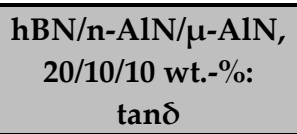 \\
\hline 0 & 0.10 & 0.09 & 0.11 & 0.16 \\
\hline 15 & 0.16 & 0.18 & 0.25 & 0.46 \\
\hline 30 & 0.17 & 0.44 & 0.18 & 0.26 \\
\hline
\end{tabular}

Table 6. Dielectric loss tand of the Nylon 12 samples at frequency of $40 \mathrm{~Hz}$.

\begin{tabular}{|c|c|c|c|c|}
\hline SOE wt.-\% & $\begin{array}{c}\text { No Particles: } \\
\tan \delta\end{array}$ & $\begin{array}{c}\text { hBN, } \\
40 \text { wt.- } \%: \\
\tan \delta\end{array}$ & $\begin{array}{c}\text { n-AlN/ } \mu-\mathrm{AlN}, \\
20 / 20 \text { wt.- } \%: \\
\tan \delta\end{array}$ & 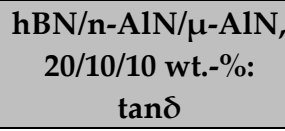 \\
\hline 0 & 0.10 & 0.07 & 0.07 & 0.07 \\
\hline 15 & 0.24 & 0.24 & 0.15 & 0.12 \\
\hline 30 & 0.14 & 0.13 & 0.13 & 0.06 \\
\hline
\end{tabular}

\section{Conclusions}

The aim of this study was to develop nanodielectrics from renewable resources. 2-Oxazoline monomers were synthesized from renewable resources (fatty acids) according to the Henkel Patent, and copolymerized via a microwave-assisted cationic ring-opening polymerization reaction. The material properties of the copoly(2-oxazoline) poly(2-nonyl-2-oxazoline)80-stat-poly(2-dec-9'-enyl-2oxazoline) 20 were compared with commercially available, fossil-based Nylon 12.

These polymers were blended with the expanding monomer SOEs, and compounded with inorganic fillers with high thermal conductivity. The samples were crosslinked and expanded by a thermally triggered dual/bi-stage curing system, comprising the crosslinking of the polyamides and SOEs according to a radical mechanism (showing volumetric shrinkage) and the (double) ringopening of the SOE according to a cationic mechanism (showing volumetric expansion).

Due to the addition of the SOE, the relative volume expansion of the Nylon 12 samples was in the range of $0.46-2.48 \%$, and in the range of $1.39-7.69 \%$ for the POx samples. Hence, the formation micro-cracks or micro-voids during curing is significantly reduced.

The unfilled POx samples show nearly the same values of tand as the unfilled Nylon 12 samples; as the POx was synthesized from renewable resources, it can be argued that this 'green' alternative shows competitive dielectric behaviour in comparison with fossil-based Nylon 12.

Author Contributions: F.B. and F.W. designed the experiments; P.M. synthesized the SOEs; F.B. and P.M. performed the experiments; F.B. and F.W. analyzed the data; F.B, P.M and F.W wrote the paper. All authors have read and agreed to the published version of the manuscript.

Acknowledgments: The research work was performed within the K-Project PolyTherm at the Polymer Competence Center Leoben GmbH (PCCL, Austria) within the framework of the COMET-program of the Federal Ministry for Climate Action, Environment, Energy, Mobility, Innovation and Technology and the Federal Ministry for Digital and Economic Affairs with contributions by the TU Graz and Montanuniversitaet Leoben. Funding is provided by the Austrian Government and the State Government of Styria.

Conflicts of Interest: Declare conflicts of interest or state. 


\section{Abbreviations}

The following abbreviations are used in this manuscript:

$\begin{array}{ll}\mathrm{AlN} & \text { aluminum nitride } \\ \mathrm{Al}_{2} \mathrm{O}_{3} & \text { aluminum oxide } \\ \mathrm{BN} & \text { boron nitride } \\ \mathrm{CROP} & \text { cationic ring-opening polymerization } \\ \mathrm{DCP} & \text { dicumyl peroxide } \\ \mathrm{DoE} & \text { design of experiments } \\ \mathrm{Dec}=\mathrm{Ox} & \text { 2-dec-9'-enyl-oxazoline } \\ \mathrm{hBN} & \text { hexagonal boron nitride } \\ \mathrm{MeOTs} & \text { methyl tosylate } \\ \mathrm{NonOx} & \text { 2-nonyl-oxazoline } \\ \mathrm{PA} & \text { polyamide } \\ \text { pNonOx80-stat-pDec=Ox20 } & \text { poly(2-nonyl-2-oxazoline)-stat-poly(2-dec-9'-enyl-2-oxazoline) } \\ \text { POx } & \text { poly(2-oxazoline) } \\ \text { SOE } & \text { spiroorthoester } \\ \text { wt.-\% } & \text { weight percent }\end{array}$

\section{References}

1. Sato, K.; Horibe, H.; Shirai, T.; Hotta, Y.; Nakano, H.; Nagai, H.; Mitsuishi, K.; Wataria, K. Thermally conductive composite films of hexagonal boron nitride and polyimide with affinity-enhanced interfaces. J. Mater. Chem. 2010, 20, 2749-2752, doi:10.1039/b924997d.

2. Marx, P.; Wanner, A.J.; Zhang, Z.; Jin, H.; Tsekmes, I.-A.; Smit, J.J.; Kern, W.; Wiesbrock, F. Effect of Interfacial Polarization and Water Absorption on the Dielectric Properties of Epoxy-Nanocomposites. Polymers 2017, 9, 195, doi:10.3390/polym9060195.

3. Choi, S.; Kim, J. Thermal conductivity of epoxy composites with a binaryparticle system of aluminum oxide and aluminum nitride fillers. Compos. Part B Eng. 2013, 51, 140-147, doi:10.1016/j.compositesb.2013.03.002.

4. Awaja, F.; Zhang, S.; Tripathi, M.; Nikiforov, A.; Pugno, N. Cracks, microcracks and fracture in polymer structures: Formation, detection, autonomic repair. Progr. Mater. Sci. 2016, 83, 536-573, doi:10.1016/j.pmatsci.2016.07.007.

5. Zhu, Y.; Romain, C.; Williams, C.K. Sustainable polymers from renewable resources. Nature 2016, 540, 354362, doi:10.1038/nature21001.

6. Glassner, M.; Vergaelen, M.; Hoogenboom, R. Poly(2-oxazoline)s: A comprehensive overview of polymer structures and their physical properties. Polym. Int. 2018, 67, 32-45, doi:10.1002/pi.5457.

7. Fimberger, M.; Tsekmes, I.A.; Kochetov, R.; Smit, J.J.; Wiesbrock, F. Crosslinked poly(2-oxazoline)s as 'green' materials for electronic applications. Polymers 2016, 8, 6, doi:10.3390/polym8010006.

8. Beck, M.; Birnbrich, P.; Eicken, U.; Fischer, H.; Fristad, W.E.; Hase, B.; Krause, H.-J. Polyoxazoline auf fettchemischer Basis. Angew. Makromol. Chem. 1994, 223, 217-233, doi:10.1002/apmc.1994.052230116.

9. Marx, P.; Romano, A.; Fischer, R.; Roppolo, I.; Sangermano, M.; Wiesbrock, F. Dual-Cure Coatings: Spiroorthoesters as Volume-Controlling Additives in Thiol-Ene Reactions. Macromol. Mater. Eng. 2019, 304, 1800627, doi:10.1002/mame.201800627.

Publisher's Note: MDPI stays neutral with regard to jurisdictional claims in published maps and institutional affiliations.

(C) 2020 by the authors. Submitted for possible open access publication under the terms and conditions of the Creative Commons Attribution (CC BY) license (http://creativecommons.org/licenses/by/4.0/). 